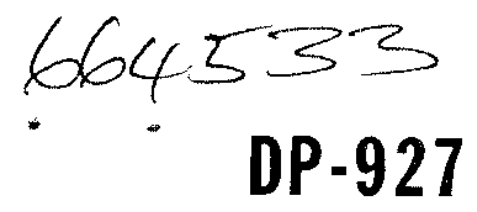

\title{
TENSOR PROPERTIES OF ORIENTED METALS
}

\author{
E. F. Sturcken
}

J. W. Croach
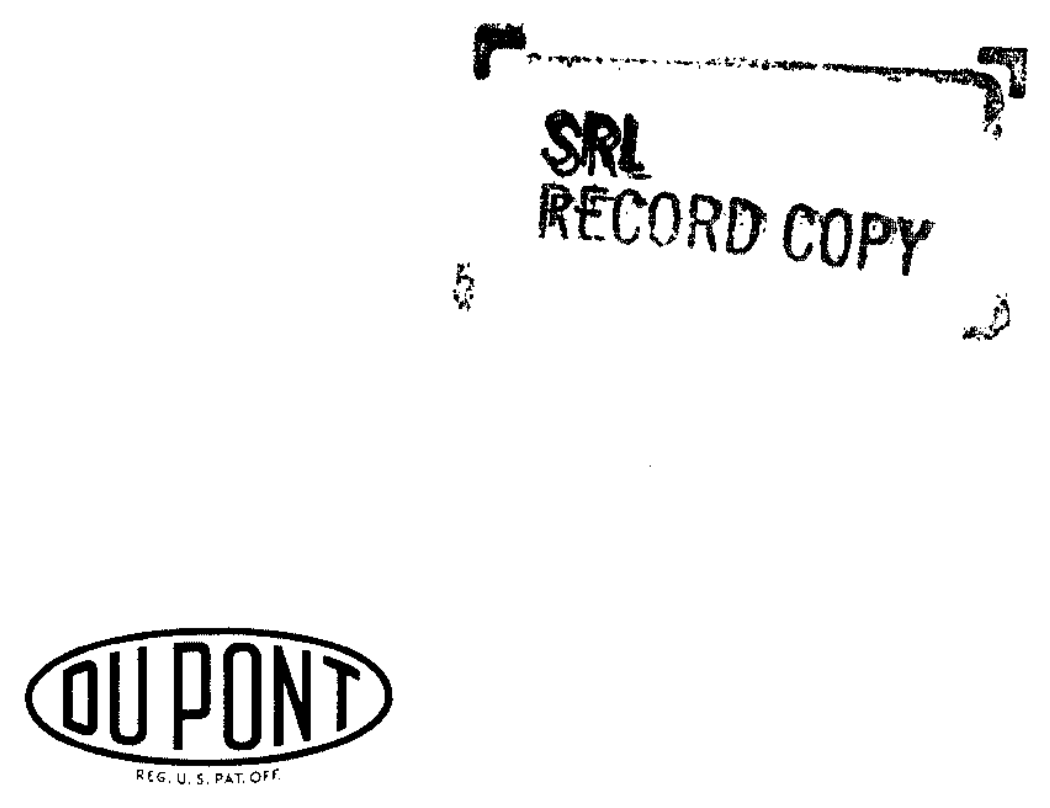

Savannah River Laboratory

Aiken, South Carolina 


\section{LEGAL NOTICE}

This report was prepared as an account of Government sponsored work. Neither the United States, nor the Commission, nor any person acting on behalf of the Commission:

A. Makes any warranty or representation, expressed or implied, with respect to the accuracy, completeness, or usefulness of the information contalned in this report, or that the use of any information, apparatus, method, or process disclosed in this report may not infringe privately owned rights; or

B. Assumes any liabilities with respect to the use of, or for damages resulting from the use of any information, apparatus, method, or process disclosed in this report.

As used in the above, "person acting on behalf of the Commission" includes any employee or contractor of the Commission, or employee of such contractor, to the extent that such employee or contractor of the Commission, or employee of such contractor prepares, disseminates, or provides access to, any information pursuant to his employment or contract with the Commission, or his employment with such contractor.

Printed in USA. Price $\$ 1.00$

Avaliable from the Cleartnghouse for Federal Sclentific

and Technical Information, National Bureau of Standards,

U. S. Department of Commerce, Springfield, Virginia 
Metals, Ceramics, and Materials

(TID-4500, 34th Ed.)

\title{
TENSOR PROPERTIES OF ORIENTED METALS
}

by

\author{
Edward F. Sturcken \\ Jesse W. Croach
}

Approved by

P. H. Permar, Research Manager

Pile Materials Division

October 1964

\footnotetext{
E. I. DU PONT DE NEMOURS \& COMPANY

SAVANNAH RIVER LABORATORY

AIKEN, SOUTH CAROLINA

CONTRACT AT(07.2)-1 WITH THE

UNITED STATES ATOMIC ENERGY COMMISSION
} 


\begin{abstract}
The theory for predicting anisotropic physical properties that result from preferred grain orientation was generalized, in analogy to the theory of linear homogeneous strain, to permit prediction of physical properties in all directions of the material from preferred orientation measurements in six or more directions. The theory is applicable to those properties that can be described to a first approximation by a second-order tensor, such as electrical resistivity, thermal coefficient of linear expansion, heat conductivity, thermal e.m.f., magnetic susceptibility, and irradiation growth.
\end{abstract}


Introduction. . . . . . . . . . . . . . 4

Summary . . . . . . . . . . . . . 6

Discussion. . . . . . . . . . . . . . 7

Development of a General Tensor for Calculating

Irradiation Growth and Thermal Expansion

Coefficients in Uranium. . . . . . . . . . . 7

Computer Program for Determining $\alpha_{i j}$ and $G_{i j}$, and
for Determining the Principal Axes . . . . .

Experimental Procedure . . . . . . . . . . 9

Experimental Proof for the General Tensor. . . . . 11

Geometrical Description of the Thermal Expansion

Coefficient Tensor for Alpha-Rolled Plate. . . . . 13

References. . . . . . . . . . . . . 16

\section{LIST OF TABLES AND FIGURES}

Table

I Calculated Versus Measured Thermal Expansion Coefficient, $\alpha_{\mathbb{N}}$, for Alpha-Rolled Uranium Plate............... . 5

II Calculated Versus Measured $G_{N}$ and $\alpha_{N}$ for Alpha-Rolled Uranium Plate. . . . . . . . . . II

II Calculated Versus Measured $G_{N}$ and $\alpha_{N}$ for Alpha-Rolled Uranium Plate. . . . . . . . . . 12

IV Computer Format Used for Calculating the General Tensor. . . . . . . . . . 14

\section{Figure}

1 Growth Rate, $G_{i}$, Versus $G_{2}$ for Unrestrained Uranium Rod. . . . . . . . . . . . . 5

2 Directions for Preferred Orientation Measurements in Rolled Uranium Sheet . . . . . . . 8

3 Metrod of Machining Specimens . . . . . . . 10

4 Strain Tensor for Thermal Expansion Coefficient of Alpha-Rolled Uranium Plate . . . . 15 


\section{TENSOR PROPERTIES OF ORIENTED METALS}

\section{INTRODUCTION}

In previous communications(1-5), a theory was developed for predicting anisotropic physical properties that result from preferred grain orientation in metals. The physical properties that were studied were thermal expansion coefficients $(4)$ and irradiation growth $(1,5)$.

The equations that were developed for predicting the physical properties were based on two assumptions:

(a) The properties of the polycrystalline aggregate were average values of the properties of the individual grains over all orientations. This assumption ignored interactions between grains, lattice distortions at the grain boundary, and any phenomena that occurred at the grain boundaries. The assumption must have been reasonably good, however, since the growth index, $G_{N},(5)$ and the thermal expansion coefficient, $\alpha_{N},(4)$ which were derived by this simple averaging process indicated good agreement between theory and experiment, as shown by the data reproduced in Table I and Figure 1.

(b) The deformation was linear and homogeneous.

The grain orientation distribution, used in the equations for predicting physical properties, was expressed mathematically as a function, $P(u, \phi)$, where $P(u, \phi)$ is the number of grains whose crystallographic axes make angles $(u, \Phi)$ with the direction in which the physical property is being predicted. The function $P(u, \phi)$ was synthesized from a set of measured relative diffraction intensities. (4)

The present report shows that the analogy to linear homogeneous strain tensor theory can be carried a step further; that is, one can develop a theory which will predict physical properties in all directions of a sample rather than in a single direction as has been the case to date.

This information was presented in abbreviated form at the 2lst Pittsburgh Diffraction Conference (November 6, 7, 8, 1963) and in detailed form at the X-Ray Preferred Orientation Meeting held at the National Lead Company of Ohio (December 5, 6, 1963). 
Calculated (a) Versus Measured Thermal Expansion Coefficient, $a_{\mathrm{N}}$, for Alpha-Rolled Uranium Plate ${ }^{(4)}$

$\begin{array}{lcc}\text { Direction } & \begin{array}{c}\text { Measured } \alpha_{\mathrm{N}}^{(7)} \\ \left(25 \text { to } 100^{\circ} \mathrm{C}\right)\end{array} & \begin{array}{l}\text { Calculated } \alpha_{\mathrm{N}} \\ \left(25 \text { to } 100^{\circ} \mathrm{C}\right)\end{array} \\ \text { Iongitudinal } & 9.2 & 9.07 \\ \text { Transverse } & 19.9 & 19.12 \\ \text { Normal } & 21.0 & 20.63\end{array}$

(a) Calculations were made using equation 4, i.e.,

$$
\begin{aligned}
\alpha_{\mathbb{N}}= & \alpha_{a} \int_{0}^{1} \int_{0}^{\pi / 2} P(u, \phi)\left(1-u^{2}\right) \sin ^{2} \phi \text { dud } \phi \\
& +\alpha_{b} \int_{0}^{1} \int_{0}^{\pi / 2} P(u, \phi)\left(1-u^{2}\right) \cos ^{2} \phi \text { dud } \phi \\
& +\alpha_{c} \int_{0}^{1} \int_{0}^{\pi / 2} P(u, \phi) u^{2} \text { dud } \phi
\end{aligned}
$$

which assumes linear homogeneous deformation.

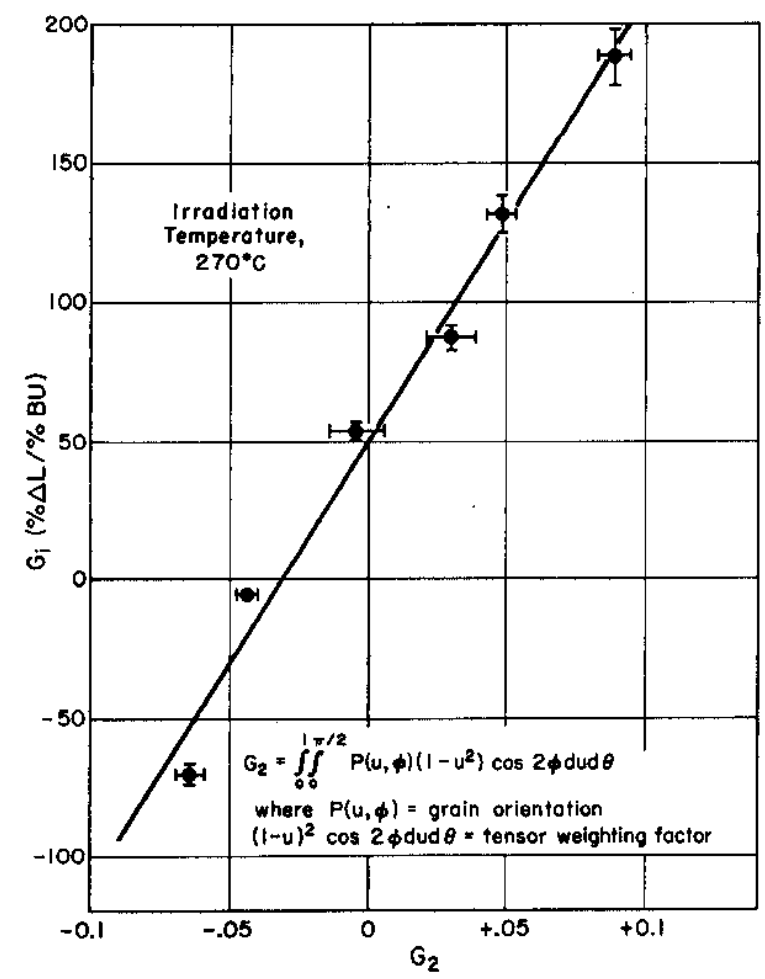

FIG. I GROWTH RATE, $G_{i}$, VERSUS $G_{2}$ FOR UNRESTRAINED URANIUM ROD $(5)$ (lrradiated in NaK Capsules) 


\section{SUMMARY}

The theory for predicting anisotropy in physical properties due to grain orientation is generalized, in analogy to the theory of homogeneous strain, to permit the prediction of physical properties in all directions of the sample from preferred orientation measurements in six or more directions. Assuming no prior knowledge of the preferred orientation, the optimum six directions are those lying along the edges of an equilateral tetrahedron.

It is shown that if $\alpha_{N}$ represents the thermal expansion coefficient, for any direction $N$, then $\alpha_{N}$ is given by the symmetric tensor

$$
a_{N}=\left(\begin{array}{lll}
a & b & c
\end{array}\right)\left(\begin{array}{lll}
\alpha_{11} & \alpha_{12} & \alpha_{13} \\
\alpha_{21} & \alpha_{22} & \alpha_{23} \\
\alpha_{31} & \alpha_{32} & \alpha_{33}
\end{array}\right)\left(\begin{array}{l}
a \\
b \\
c
\end{array}\right)
$$

where $a, b$, and $c$ are the direction cosines which the direction $\mathrm{N}$ makes with a set of orthogonal axes.

If $P(u, \phi)$ is measured for six or more directions, then $\alpha_{N}$ can be calculated for the six directions and the $\alpha_{i j}$ determined by matrix inversion from the above equation. A parallel treatment is valid for the growth index $G_{\mathrm{N}}$.

The theory was tested on a section of hot-rolled uranium sheet on which preferred orientation measurements were made to determine $\alpha_{N}$ in 15 directions of the sheet. The $\alpha_{\mathbb{N}}$ for six directions were used to determine the $\alpha_{i j}$. The $\alpha_{\mathbb{N}}$ calculated for all 15 directions from these $\alpha_{i j}$ were in good agreement with the measured values of $\alpha_{\mathbb{N}}$ for the 15 directions. The $\alpha_{i j}$ are also determined from a least-squares fit of the data for all 15 directions. These $\alpha_{i j}$ give $\alpha_{N}$ which are in better agreement with the measured $\alpha_{N}$ than the $\alpha_{i j}$ determined from six directions.

An IBM-704 computer program was written which, beginning with the $\alpha_{N}$ and their corresponding direction cosines $a, b$, and $c$, computes the $\alpha_{i j}$, the principal roots, the direction cosines of the principal axes, compares measured $\alpha_{N}$ with calculated $\alpha_{N}$, and calculates the determinant of the matrix used to compute the $\alpha_{i j}$, the correlation coefficient, and the standard deviation of the least-squares fit used to compute the $\alpha_{i j}$. 


\section{DISCUSSION}

DEVELOPMENT OF A GENERAL TENSOR FOR CALCULATING IRRADIATION GROWTH AND THERMAL EXPANSION COEFFICIENTS IN URANIUM

For the case of linear homogeneous elastic strain, the strain in any direction, $N$, can be represented by an equation for a surface of second degree, (B) i.e.,

$$
\epsilon_{N}=\epsilon_{11} a^{2}+\epsilon_{22} b^{2}+\epsilon_{33} c^{2}+2 \epsilon_{12} a b+2 \epsilon_{13} a c+2 \epsilon_{23} b c
$$

where $a, b$, and $c$ are the direction cosines of direction $N$; $\epsilon_{11}, \epsilon_{22}$, and $\epsilon_{33}$ are the normal strains; and $\epsilon_{12}, \epsilon_{13}$, and $\epsilon_{23}$ are the shear strains. Since there are only six strain coefficients, a knowledge of $\epsilon_{\mathrm{N}}$ in six directions will permit solution of equation 1 for the $\epsilon_{i j}$ and thereby permit calculation of $\epsilon_{\mathbb{N}}$ in any direction. A convenient form for expressing equation ' $l$ is the symmetric tensor (i.e., $\left.\epsilon_{i j}=\epsilon_{j i}\right)$.

$$
\epsilon_{N}=\left(\begin{array}{lll}
a & b & c
\end{array}\right)\left(\begin{array}{lll}
\epsilon_{11} & \epsilon_{12} & \epsilon_{13} \\
\epsilon_{21} & \epsilon_{22} & \epsilon_{23} \\
\epsilon_{31} & \epsilon_{32} & \epsilon_{33}
\end{array}\right)\left(\begin{array}{l}
a \\
b \\
c
\end{array}\right)
$$

If the assumption is made that the nature of $\alpha_{N}$ and $G_{N}$ is such that they can be described by an equation of the type employed to describe linear homogeneous deformation, i.e., equation 2, then

$$
a_{N}=\left(\begin{array}{lll}
a & b & c
\end{array}\right)\left(\begin{array}{lll}
a_{11} & a_{12} & a_{13} \\
a_{21} & a_{22} & a_{23} \\
a_{31} & a_{32} & a_{33}
\end{array}\right)\left(\begin{array}{l}
a \\
b \\
c
\end{array}\right)
$$

or $\alpha_{N}=\alpha_{11} a^{2}+\alpha_{22} b^{2}+\alpha_{33} c^{2}+2 \alpha_{12} a b+2 \alpha_{13} a c+2 \alpha_{23} b c$

and

$$
G_{N}=\left(\begin{array}{lll}
a & b & c
\end{array}\right)\left(\begin{array}{lll}
G_{11} & G_{12} & G_{13} \\
G_{21} & G_{22} & G_{23} \\
G_{31} & G_{32} & G_{33}
\end{array}\right)\left(\begin{array}{l}
a \\
b \\
c
\end{array}\right)
$$

or $G_{N}=G_{11} a^{2}+G_{22} b^{2}+G_{33} c^{2}+2 G_{12} a b+2 G_{13} a c+2 G_{23} a c$

As in the case of the strain tensor, the values of $\alpha_{i j}$ and $G_{i j}$ may be determined in a straightforward fashion if six (or more) values of $\alpha_{N}$ and $G_{N}$ are known. A given value of $\alpha_{N}$ or $G_{N}$ is calculated from the equations $(4,2)$ 


$$
\begin{aligned}
& \alpha_{N}=\left[\alpha_{a} \int_{0}^{1} \int_{0}^{\pi / 2} P(u, \phi)\left(1-u^{2}\right) \sin ^{2} \phi d u d \phi\right. \\
& +a_{b} \int_{0}^{2} \int_{0}^{\pi / 2} P(u, \phi)\left(1-u^{2}\right) \cos ^{2} \phi d u d \phi \\
& \left.+\alpha_{c} \int_{0}^{1} \int_{0}^{\pi / 2} P(u, \phi) u^{2} \operatorname{dud} \phi\right] \div \int_{0}^{1} \int_{0}^{\pi / 2} P(u, \phi) d u d \phi \\
& \text { and } G_{N}=\left[\int_{0}^{1} \int_{0}^{\pi / 2} P(u, \phi)\left(I-u^{2}\right) \cos 2 \phi d u d \phi\right] \div \int_{0}^{1} \int_{0}^{\pi / 2} P(u, \phi) d u d \phi
\end{aligned}
$$

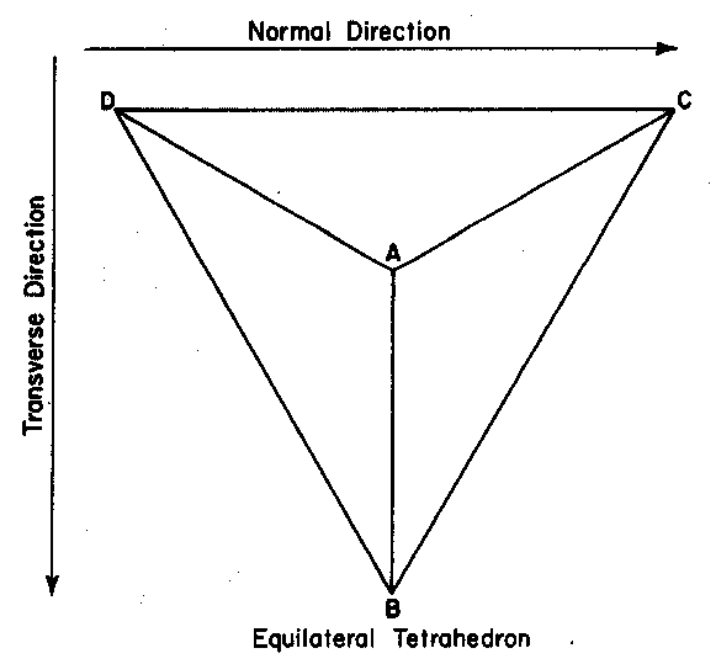

FIG. 2 DIRECTIONS FOR PREFERRED ORIENTATION MEASUREMENTS IN ROLLED URANIUM SHEET 
It is well known that a set of coordinate axes can always be found in which the cross terms in $a, b$, and $c$ of equation 1 will vanish, i.e.,

$$
\epsilon_{N}=\epsilon_{11} a^{2}+\epsilon_{22} b^{2}+\epsilon_{33} c^{2}
$$

We call these strains the principal strains (or principal roots) and the axes the principal axes. Similarly, for $\alpha_{N}$ and $G_{N}$.

and

$$
a_{N}=a_{11} a^{2}+\alpha_{22} b^{2}+a_{33} c^{2}
$$

If the principal directions are known a priori, then $\alpha_{N}$ or $G_{N}$ need be measured only along these principal directions to determine $\alpha_{\mathrm{N}}$ or $\mathrm{G}_{\mathrm{N}}$ in all directions.

\section{COMPUTER PROGRAM FOR DETERMINING $\alpha_{i j}$ OR $G_{i j}$, AND FOR DETERMINING THE PRINCIPAL AXES}

An IBM- 704 computer program was already available (2) for computing $\alpha_{N}$ or $G_{N}$ and these values along with the direction cosines provide the input data for the new IBM-704 computer program. The computer program employs matrix inversion to determine $\alpha_{i j}$. If more than $s_{i x} \alpha_{N}$ are fed in as data then a least-squares method is used to determine $\alpha_{1 j}$. Having determined $\alpha_{i j}$, the computer then determines the principal axes and the principal roots. The format consists of input data, $\alpha_{i j}$, calculated versus measured $\alpha_{N}$, the correlation coefficient of the least-squares fit, the standard deviation, the value of the determinant of the matrix used in the computation of $\alpha_{i j}$, the principal roots and the direction cosines of the principal roots. A typical format is shown as Table IV. The computer program is available at the Savannah River Laboratory.

\section{EXPERIMENTAL PROCEDURE}

The material selected for the experimental verification of the above treatment was a section of alpha-rolled uranium sheet. Samples were prepared as described in Reference 1 for 15 directions of the plate. To get the most uniform distribution for the first six directions, they were machined 
along directions corresponding to the edges of an equilateral tetrahedron as illustrated in Figure 3. The other nine directions were chosen so as to require a minimum amount of additional machining. The techniques used to machine the samples are illustrated in Figure 3.

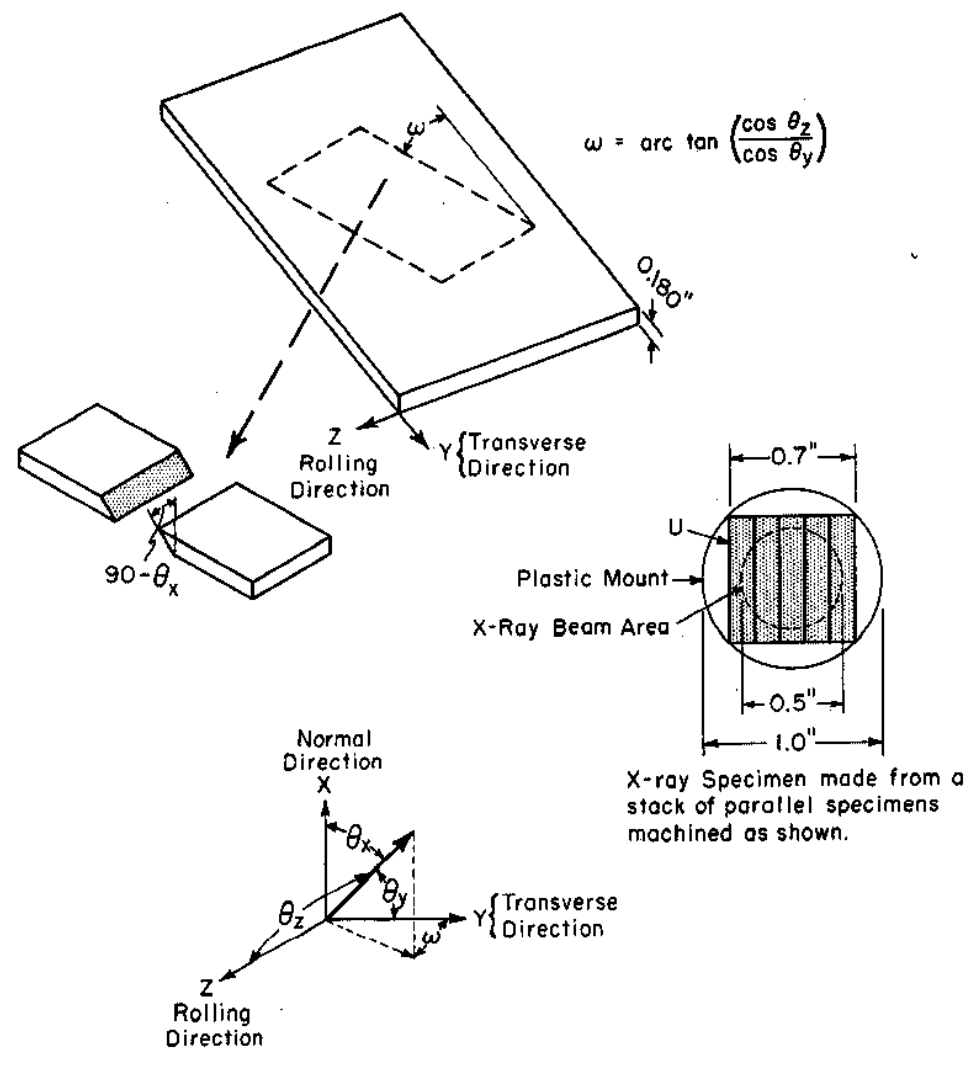

FIG. 3 METHOD OF MACHINING SPECIMENS

Prior to preparing the samples, 50 mus were made at different depths in the normal direction of the plate. The data showed a 0.005 -inch texture gradient on the outer surfaces of the plate; these surfaces were ground off to remove the texture gradient before the samples were prepared for the final measurements.

The integrated diffraction intensities for 20 planes (hkl) of uranium were measured for each direction with an automated Norelco diffractometer and a scintillation detector. The planes used are given in Reference 2. Fifteen runs were made on each sample, at 15 different depths with mechanical and electropolishing at each depth. The 15 runs assured a sufficient statistical population of grains and care was taken to remove all cold work by electropolishing before each run. The 95\% confidence interval of the mean of the measured values for each sample is given in Table III. 


\section{EXPERIMENTAL PROOF FOR THE GENERAL TENSOR}

The validity of the assumption that $\alpha_{N}$ and $G_{N}$ can be represented by a tensor of the same form as that used for linear homogeneous deformation was demonstrated by comparing the values of $\alpha_{N}$ and $G_{N}$ obtained from the preferred orientam tion measurements using equations 7 and 8 with those calculated from equations 3 and 5 . First, $\alpha_{N}$ and $G_{N}$ were calculated from the $P(u, \phi)$ for each of the 15 directions. These are called measured $\alpha_{N}$ and $G_{N}$ since each $P(u, \phi)$ is determined from a set of measured diffraction intensities from a particular direction in the sample. Six of the measured $\alpha_{N}$ and $G_{N}$ were used to determine $\alpha_{i j}$ and $G_{1 j}$ (by matrix inversion). These values of $G_{i j}$ and $\alpha_{i j}$ were then used to calculate $\alpha_{N}$ and $G_{N}$ for the other nine directions using equations 3 and 5 . The calculated and measured $G_{N}$ and $\alpha_{N}$ are compared in Table II.

\section{TABIEII}

Calculated Versus Measured $G_{N}$ and $\alpha_{N}$ for Alpha-Rolled Uranium Plate

(Six directions chosen along edges of equilateral tetrahedron)

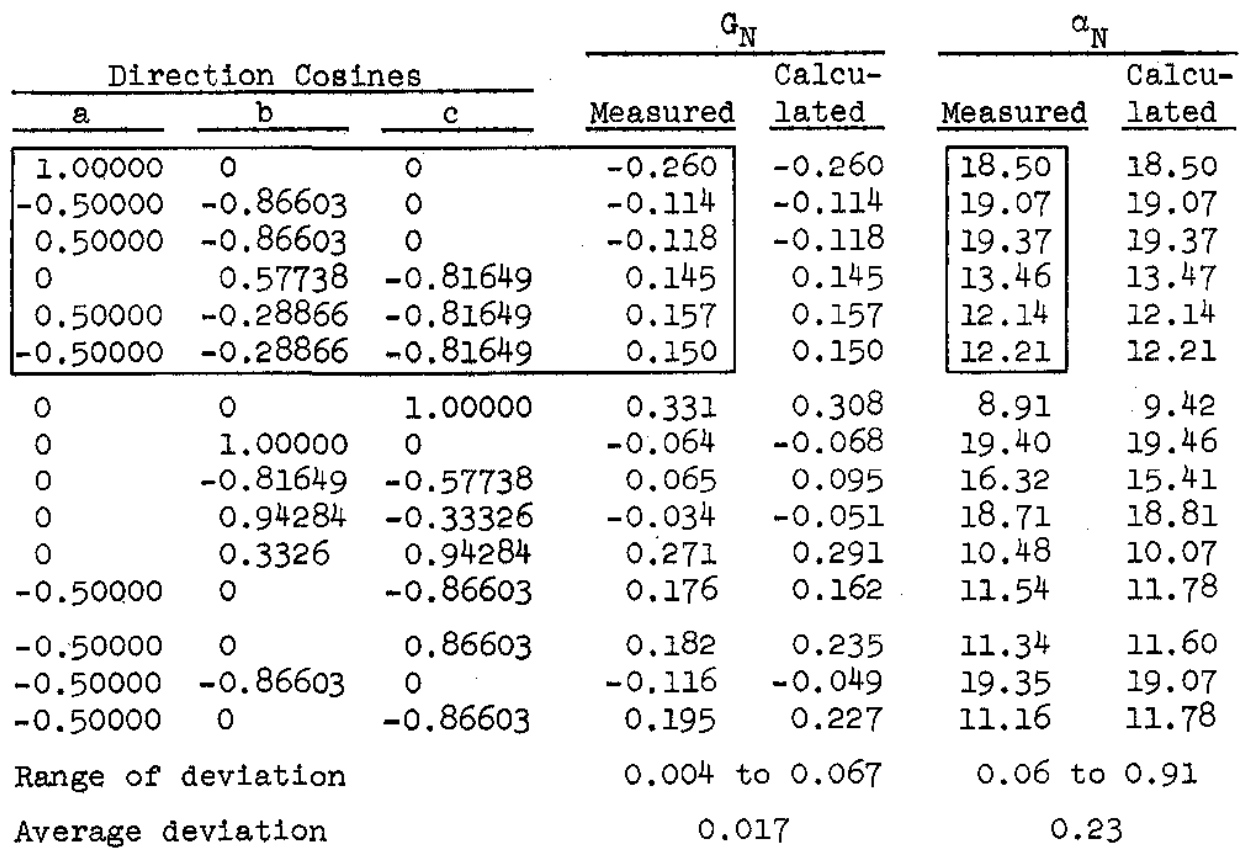

NOTE: The "boxed" data were used to calculate the $\alpha_{1 j}$ and $G_{1 j}$. The $G_{N}$ and $\alpha_{N}$ data listed under "Calculated" were calculated from these $\alpha_{1 j}$ and $G_{1 j}$ using equations 3 and 5 . The term "Measured $\alpha_{N}$ and $G_{N}$ " means $\alpha_{N}$ and $G_{N}$ calculated from equations 7 and 8 using the measured $P(u, \phi)$ distribution function. 
The agreement between theory and experiment is good. As a further refinement all 15 directions were used to determine, by least-squares fitting, the best set of $\alpha_{1 j}$ and $G_{1 j}$. The measured and calculated $\alpha_{N}$ and $G_{N}$ for these $\alpha_{i, j}$ and $G_{i j}$ are shown in Table III. The agreement is excellent.

\section{TABIE III}

Calculated Versus Measured $\mathrm{G}_{\mathrm{N}}$ and $\alpha_{\mathrm{N}}$ for Alpha-Rolled Uranium Plate

(Fifteen directions, includes the six directions employed in Table II)

\begin{tabular}{|c|c|c|}
\hline$a$ & $b$ & $c$ \\
\hline $\begin{array}{r}1.00000 \\
-0.50000 \\
0.50000 \\
0 \\
0.50000\end{array}$ & $\begin{array}{r}0 \\
-0.86603 \\
-0.86603 \\
0.57738 \\
-0.28866\end{array}$ & $\begin{array}{l}0 \\
0 \\
0 \\
-0.816 \\
-0.816\end{array}$ \\
\hline $\begin{array}{l}0.50000 \\
0 \\
0 \\
0 \\
0\end{array}$ & $\begin{array}{l}-0.28866 \\
0 \\
1.00000 \\
-0.81649 \\
0.94284\end{array}$ & $\begin{array}{l}-0.8164 \\
1.0000 \\
0 \\
-0.5773 \\
-0.3332\end{array}$ \\
\hline $\begin{array}{l}0 \\
-0.50000 \\
-0.50000 \\
-0.50000 \\
-0.50000\end{array}$ & $\begin{array}{l}0.33326 \\
0 \\
0 \\
-0.86603 \\
0\end{array}$ & $\begin{array}{r}0.9428 \\
-0.8660 \\
0.8660 \\
0 \\
-0.8660\end{array}$ \\
\hline
\end{tabular}

Average deviation

Range of deviation

Average $95 \%$ confldence

limit of measured values

\begin{tabular}{|c|c|c|c|}
\hline \multicolumn{2}{|c|}{$G_{N}$} & \multicolumn{2}{|c|}{$a_{N}$} \\
\hline Measured & $\begin{array}{l}\text { Calcu- } \\
\text { Iated }\end{array}$ & Measured & $\begin{array}{l}\text { Calcu- } \\
\text { lated }\end{array}$ \\
\hline $\begin{array}{r}-0.260 \\
-0.114 \\
-0.118 \\
0.145 \\
0.157\end{array}$ & $\begin{array}{r}-0.252 \\
-0.117 \\
-0.118 \\
0.170 \\
0.151\end{array}$ & $\begin{array}{l}18.50 \\
19.07 \\
19.37 \\
13.47 \\
12.14\end{array}$ & $\begin{array}{l}18.32 \\
19.27 \\
19.44 \\
12.97 \\
12.26\end{array}$ \\
\hline $\begin{array}{r}0.150 \\
0.331 \\
-0.064 \\
0.065 \\
-0.034\end{array}$ & $\begin{array}{r}0.154 \\
0.318 \\
-0.072 \\
0.076 \\
-0.041\end{array}$ & $\begin{array}{r}12.21 \\
8.91 \\
19.40 \\
16.32 \\
18.71\end{array}$ & $\begin{array}{r}12.20 \\
9.21 \\
19.70 \\
15.94 \\
18.71\end{array}$ \\
\hline $\begin{array}{r}0.271 \\
0.176 \\
0.182 \\
-0.116 \\
0.195\end{array}$ & $\begin{array}{r}0.287 \\
0.177 \\
0.174 \\
-0.117 \\
0.177\end{array}$ & $\begin{array}{l}10.48 \\
11.54 \\
11.34 \\
19.35 \\
11.16\end{array}$ & $\begin{array}{l}10.21 \\
11.49 \\
11.49 \\
19.27 \\
11.49\end{array}$ \\
\hline \multicolumn{2}{|c|}{0.009} & \multicolumn{2}{|c|}{0.20} \\
\hline \multicolumn{2}{|c|}{0 to 0.025} & \multicolumn{2}{|c|}{0 to 0.50} \\
\hline \multicolumn{2}{|c|}{0.009} & \multicolumn{2}{|c|}{0.13} \\
\hline
\end{tabular}

NOTE: The "Measured $\alpha_{N}$ and $G_{N}$ " were computed from equations 7 and 8 using the measured $P(u, \phi)$. The "Calculated $\alpha_{N}$ and $G_{N}$ " were computed from equations 3 and 5 . The $\alpha_{1 j}$ and $G_{1 j}$ used in equations 3 and 5 were determined by least squares from all 15 measured $\alpha_{\mathbb{N}}$ and $\mathrm{G}_{\mathrm{N}}$.

Hence, $\alpha_{N}$ and $G_{N}$ have been shown to have a tensor form which can be described by an equation of the second degree. Although measurements in only an arbitrary six directions are needed to determine the coefficients, $\alpha_{i j}$ and $G_{i j}$, of the equations, comparison of Tables II and III shows that the more directions one measured the greater the precision of $\alpha_{i j}$ and $G_{i j}$. 
GEOMETRICAL DESCRIPTION OF THE THERMAL EXPANSION COEFFICIENT TENSOR FOR ALPHA-ROLLED PLATE

If the coordinate axes are taken in the direction of the principal axes, then equation 4 reduces to equation 10 and

$$
x=\alpha_{11} a, \quad y=\alpha_{22} b, \quad \text { and } z=\alpha_{33} c
$$

where $x, y$, and $z$ are the principal axes and $\alpha_{1.1}, \alpha_{22}$, and $\alpha_{33}$ are the principal roots.

Putting these values for $a, b$, and $c$ into the identity relation for the direction cosines, $a^{2}+b^{2}+c^{2}=1$, we obtain

$$
\frac{x^{2}}{a_{11}{ }^{2}}+\frac{y^{2}}{a_{22}{ }^{2}}+\frac{z^{2}}{a_{33^{2}}}=1
$$

which is the equation of an ellipsoid when $\alpha_{11}, \alpha_{22}$, and $\alpha_{33}$ are all positive. The principal roots $\alpha_{11}, \alpha_{22}$, and $\alpha_{33}$ for alpha-rolled plate, given in Table IV, are all positive. For this condition, the surface is an ellipsold as shown in Figure 4. The principal directions are nearly coincident with the fabrication directions. The thermal expansion coefficient for any direction in the plate may be obtained from Figure 4 by constructing a vector from the origin, in the given direction, to the surface of the ellipsoid. The length of the vector is the thermal expansion coefficient $\alpha_{N}$. For the plate studied, the $\alpha_{N}$ is minimum in the rolling direction and about equal in the transverse and normal directions. 
TABLE IV

Computer Format Used for Calculating the Genera1 Tensor

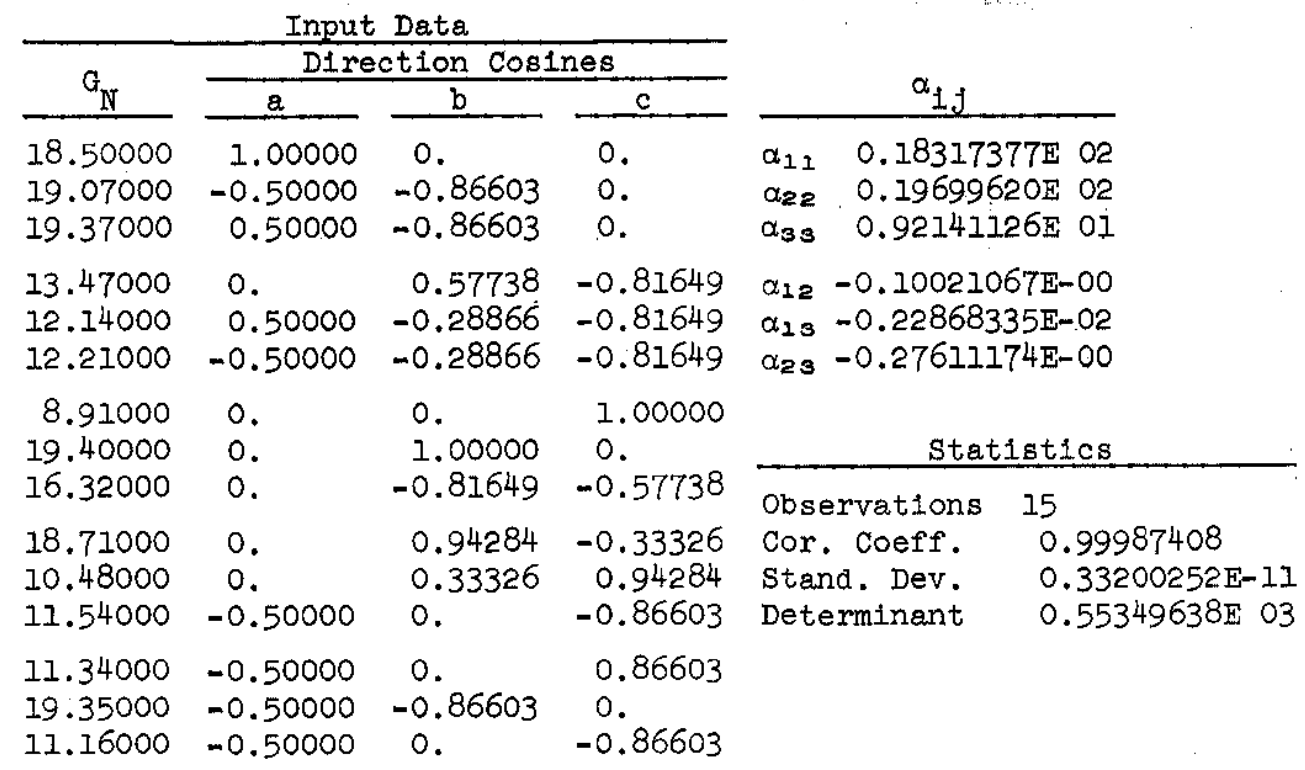

Respectively Actual and Fitted Values

\begin{tabular}{rrrrrr}
\hline 18.50000 & 18.31738 & 19.07000 & 19.26743 & 19.37000 & 19.44100 \\
13.47000 & 12.97019 & 12.14000 & 12.26409 & 12.21000 & 12.20250 \\
8.91000 & 9.21411 & 19.40000 & 19.69962 & 16.32000 & 15.94422 \\
18.71000 & 18.70878 & 10.48000 & 10.20523 & 11.54000 & 11.48802 \\
11.34000 & 11.49198 & 19.35000 & 19.26743 & 11.16000 & 11.48802
\end{tabular}

Principal Roots

$1 \quad 0.18310224 \mathrm{E} 02$

$20.92068437 \mathrm{E}$ OI

$3 \quad 0.19714042 \mathrm{E} \mathrm{O2}$
Direction Cosines for Princlpal Axes

$\begin{array}{lrrr}\text { Root (1) } & -0.99744 & -0.07146 & 0.00242 \\ \text { Root (2) } & 0.00064 & 0.02631 & 0.99965 \\ \text { Root (3) } & 0.07129 & -0.99711 & 0.02621\end{array}$




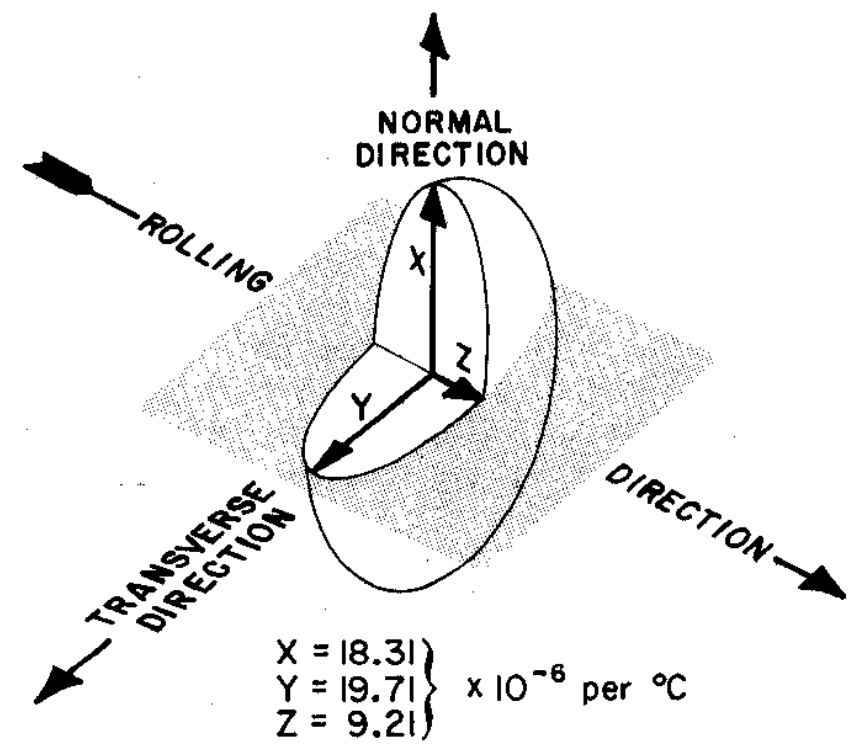

FIG. 4 STRAIN TENSOR FOR THERMAL EXPANSION COEFFICIENT OF ALPHA-ROLLED URANIUM PLATE 


\section{REFERENCES}

1. E. F. Sturcken and W. R. McDonell. "An X-Ray Method for Predicting Anisotropic Irradiation Growth in Uranium." J. Nucl. Mat. I, No. 1, 85-91 (1962).

2. E. F. Sturcken. "A Generalized Growth Index Formalism." USAEC Report NICO-804, pp. 9-24, National Lead Co., Cincinnati, Ohio (1960).

3. E. F. Sturcken and J. W. Croach. "Quantitative Interpretation of Preferred Orientation Measurements." Eighteenth Annual Pittsburgh Diffraction Conference, November 9-11, 1960.

4. E. F. Sturcken and J. W. Croach. "Predicting Physical Properties in Oriented Metals." Trans. AIME 227, 934-40 (1963).

5. E. F. Sturcken, B. G. LeFevre, and W. R. McDonell. "Anisotropic Growth vs Preferred Orientation in Unrestrained Uranium." USAEC Report NMI-4992, pp. 18-42, Nuclear Metals, Inc., West Concord, Mass. (1963).

6. S. Timoshenko and J. N. Goodier. Theory of Elasticity. McGraw-Hill, New York (195I).

7. W. R. McDone11. Quantitative Correlation of Irradiation Growth with Preferred Orientation in Uranium. USAEC Report DP-420, E. I. du Pont de Nemours \& Co., Savannah River Laboratory, Aiken, S. C. (1960). 